\title{
PILE MODEL TESTS USING STRAIN GAUGE TECHNOLOGY
}

\author{
ADAM KRASIŃSKI, TOMASZ KUSIO \\ Gdańsk University of Technology, Department of Geotechnics, Geology and Marine Civil Engineering, \\ ul. Narutowicza 11/12,80-233 Gdańsk, Poland. E-mail: akra@pg.gda.pl; tomkusio@pg.gda.pl
}

\begin{abstract}
Ordinary pile bearing capacity tests are usually carried out to determine the relationship between load and displacement of pile head. The measurement system required in such tests consists of force transducer and three or four displacement gauges. The whole system is installed at the pile head above the ground level. This approach, however, does not give us complete information about the pile-soil interaction. We can only determine the total bearing capacity of the pile, without the knowledge of its distribution into the shaft and base resistances. Much more information can be obtained by carrying out a test of instrumented pile equipped with a system for measuring the distribution of axial force along its core. In the case of pile model tests the use of such measurement is difficult due to small scale of the model.

To find a suitable solution for axial force measurement, which could be applied to small scale model piles, we had to take into account the following requirements:

- a linear and stable relationship between measured and physical values,

- the force measurement accuracy of about $0.1 \mathrm{kN}$,

- the range of measured forces up to $30 \mathrm{kN}$,

- resistance of measuring gauges against aggressive counteraction of concrete mortar and against moisture,

- insensitivity to pile bending,

- economical factor.

These requirements can be fulfilled by strain gauge sensors if an appropriate methodology is used for test preparation (Hoffmann [1]). In this paper, we focus on some aspects of the application of strain gauge sensors for model pile tests. The efficiency of the method is proved on the examples of static load tests carried out on SDP model piles acting as single piles and in a group.
\end{abstract}

Key words: screw displacement piles, CFA piles, deep foundation, model tests, group of piles

\section{LIST OF SYMBOLS}

$q_{c}-$ unit CPT cone resistance,

$Q_{t} \quad$ - total load of pile,

$Q_{b}-$ pile base resistance,

$Q_{s}$ - pile shaft resistance,

$Q_{u l t}$ - ultimate load of pile (ultimate bearing capacity of pile).

\section{INTRODUCTION}

The standard method of strain gauge measurement is based on the linear relationship between electric resistance and strain of the gauge. If this approach is to be used to determine the force value in concrete pile core, one needs to precisely determine the elastic modulus and cross-sectional area of the pile at the point of gauge installation. These values are difficult to measure, as we have to remember that during the test the pile is hidden in the ground and there is no access to the measuring points. Moreover,

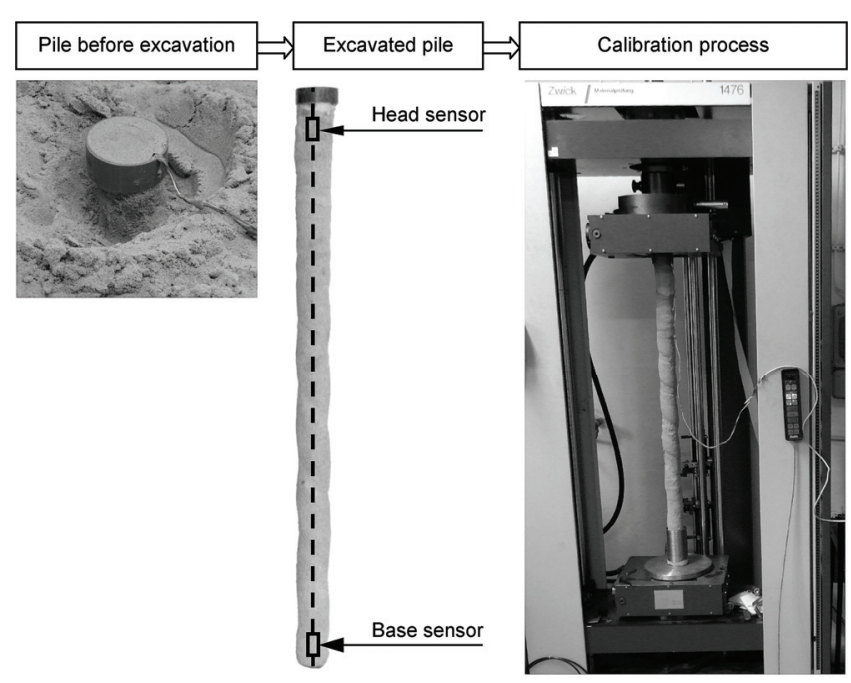

Fig. 1. Model pile calibration and sensors localization in pile core 
even small inaccuracies in pile cross-section or elastic modulus identification cause significant errors in the determination of the internal force. A more reliable approach is to use a calibration procedure as shown in Fig. 1.

In this method, we determine a direct correlation between the force value and the electric signal of strain gauge bridge. In this way, all measurement difficulties and errors mentioned above are eliminated. This approach was applied e.g. by Krasiński [2], [3]. Further development of this method is presented in this paper.

\section{ACCURACY OF MEASUREMENT SYSTEM}

The measurement accuracy of the technique described depends on the elasticity of pile material and on the gauge construction. The range of elasticity should also be matched to the expected range of pile loads. In order to verify the deformability of pile material, tests of cylindrical samples were performed previously (see Fig. 2).
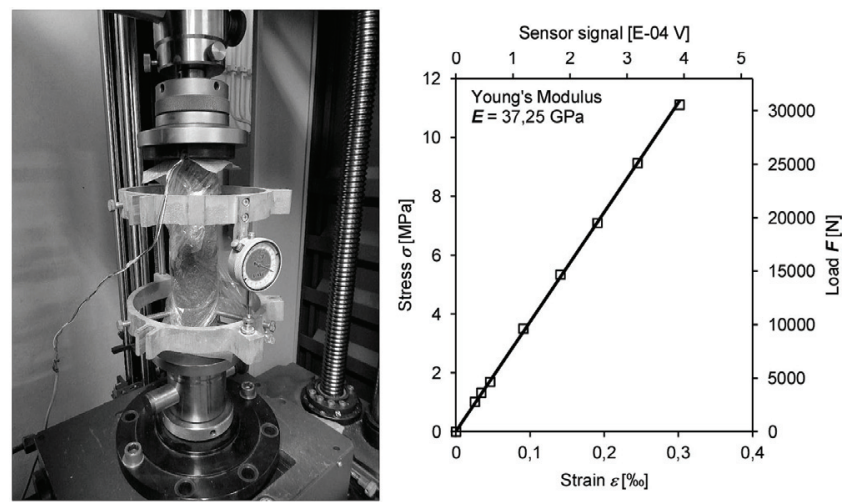

Fig. 2. Deformability tests for cylindrical samples and Young's modulus

The plot in Fig. 2 shows that the material used for pile models offers very good elastic properties and provides an accuracy of force measurement of $0.1 \mathrm{kN}$ in the range up to $30 \mathrm{kN}$ (the measuring device provides data with resolution of $1.0 \mathrm{E}-06 \mathrm{~V}$ ).

\section{THE CONSTRUCTION OF SENSORS}

The small scale of pile models affects the design of transducers. To adjust the size of the gauges to the inner diameter of the SDP auger rod, they were designed as plexiglass rollers of $8 \mathrm{~mm}$ in diameter and $15 \mathrm{~mm}$ in length.

Preliminary tests have shown that in the case of pile groups, where the loads on pile heads can act eccentrically, single gauge sensor readings do not lead to correct results (Krasiński and Kusio [4]). To avoid errors in measurement, two types of sensors were prepared. The first one was a single gauge sensor for measuring axial force at the pile base and the second one was a triple gauge sensor for measuring force at the pile head. Differences in construction of single and triple gauge sensors are shown in Fig. 3. The second type was insensitive to bending and was used in the tests of pile groups, where the loads of pile heads were eccentric causing internal bending moments in piles. These sensors were installed in two places of the pile. Sensors of the first type were installed $3 \mathrm{~cm}$ above pile base, whereas sensors of the second type were installed about $5 \mathrm{~cm}$ below surface of pile head ( $5 \mathrm{~cm}$ below the base of foundation plate).

To avoid moisture penetration and mechanical damage all sensors were protected by a special coating, consisting of a base layer, a mechanical protective layer and moisture barrier.

Each transducer was connected by a three-cable system to the rest of Wheatstone bridge. Signals were transmitted by a high resolution analog-to-digital converter and as a digital signal recorded in computer memory.

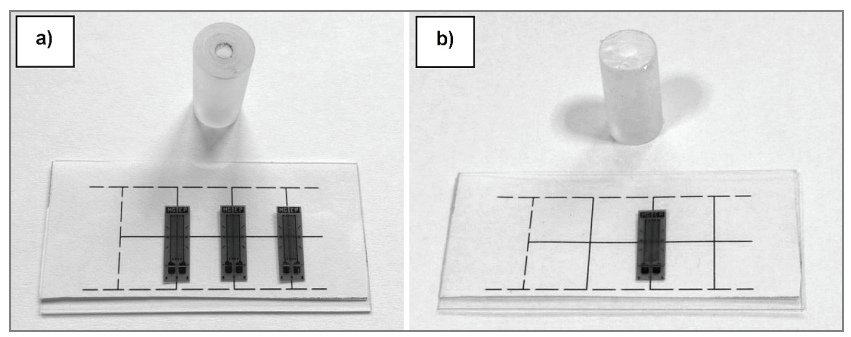

Fig. 3. Two types of sensors before gluing gauges: (a) for eccentric loading, (b) for axial loading

\section{EXAMPLES OF APPLICATION}

The transducers described above were applied to measure axial forces in four models of SDP piles tested separately as single piles and in one test of a group of nine model SDP piles. These tests were conducted to compare the interaction between pile and soil for single SDP piles and for the same piles acting in a group. 
The procedures of soil preparation, model piles installation, construction of foundations and loading tests were described in our previous paper (Krasiński and Kusio [4]).

Both tests (single and group) were performed in the same soil conditions which are presented in Fig. 4.

All the measured values, like external load, settlements and internal sensor readings were recorded every five seconds. Such a dense sampling allowed readings to be filtered and errors to be determined. As an example, in Fig. 5, we present the changes of axial force in one of the piles, obtained from strain gauge sensors.
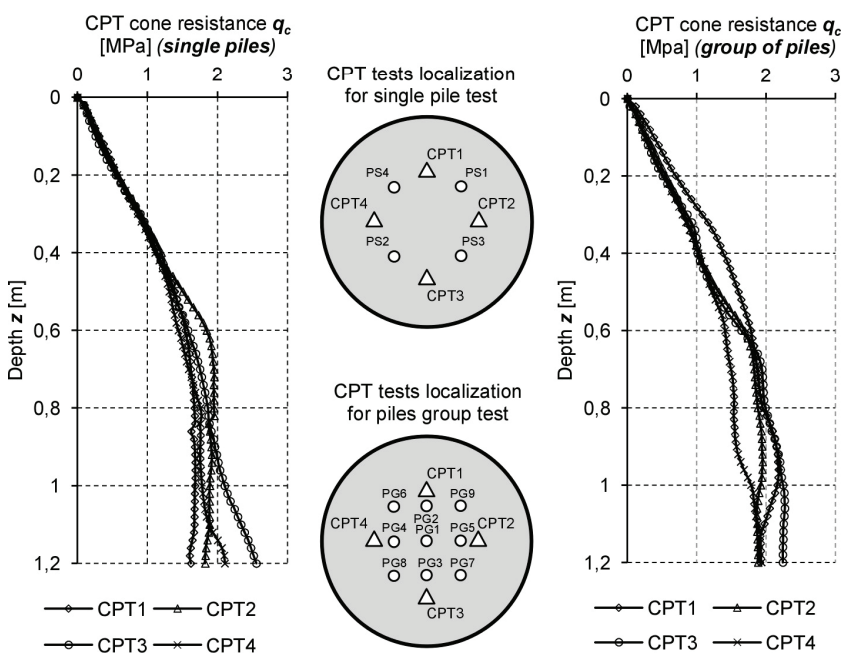

Fig. 4. Soil conditions in single pile and group tests presented as a distribution of $q_{c}$ with CPT tests localization

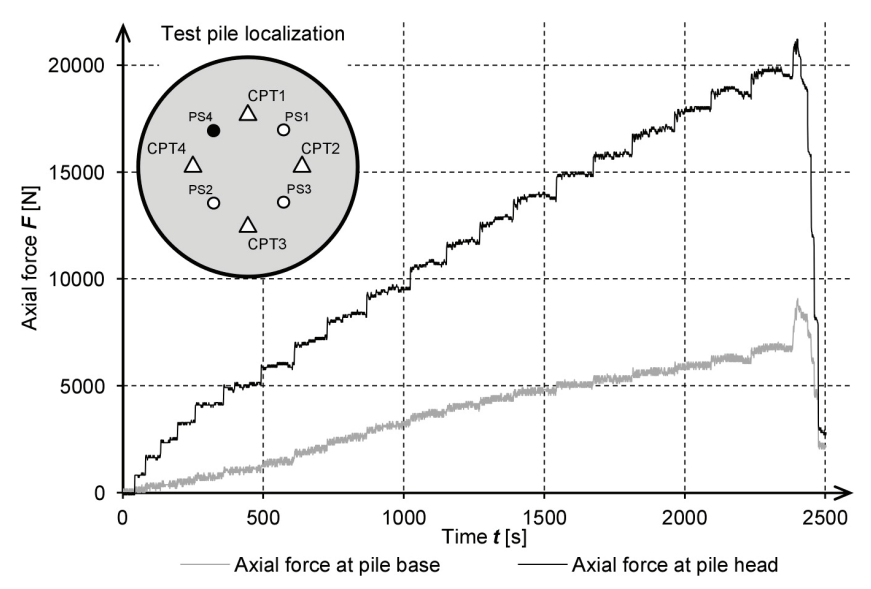

Fig. 5. Axial force changes during the load test of single SDP pile no. PS4

In the case of a single SDP pile load test, two measuring channels for axial force distribution and three channels for settlements were used. In the case of a group of nine piles much more measuring channels were needed. To measure load and axial force values in all piles at the same time, eighteen channels had to be applied with four additional channels for measuring settlements of the foundation slab. For this purpose, a special measuring system consisting of thirty two channels for strain gauge transducers and eight channels for analog signals (from displacement transducers) was assembled (see Fig. 6).
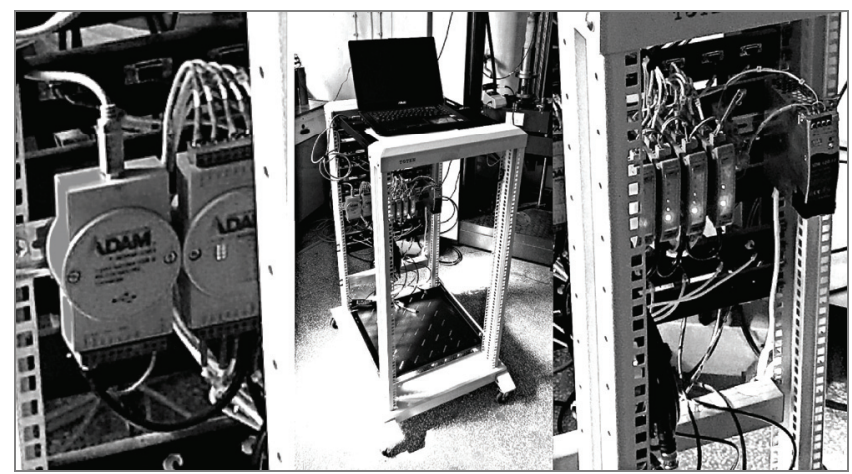

Fig. 6. Multi-channel measuring equipment

\section{ANALYSIS OF TEST RESULTS}

To compare the behavior of single piles and group piles the load-settlement diagrams of selected piles are shown together in Fig. 7.

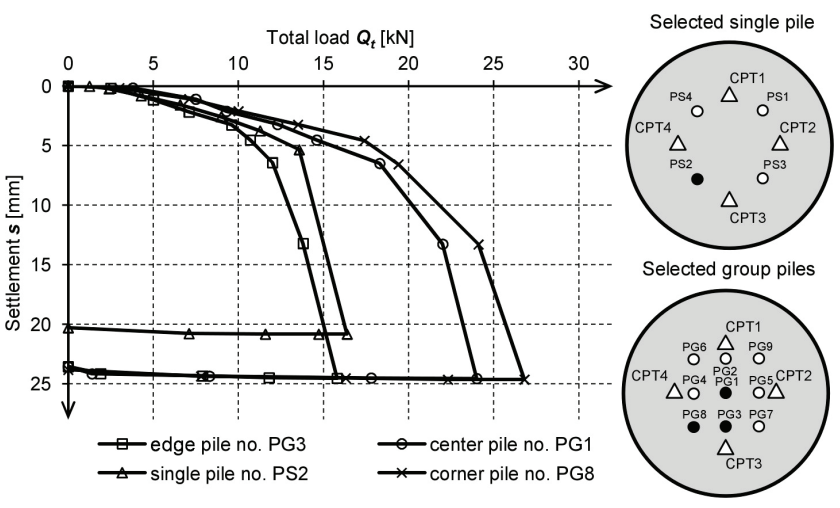

Fig. 7. Load-settlement characteristics of selected SDP piles in group compared with characteristic of a single SDP pile

We can note that the bearing capacity of the center and corner piles in group is greater than the bearing capacity of a single pile. In the case of edge pile, its bearing capacity is smaller than that of a single pile.

The measurement provided by sensors installed inside the pile allowed the load-settlement characteristics of shaft and base resistances to be determined for each pile separately. A comparison of these characteristics is presented in Fig. 8. 

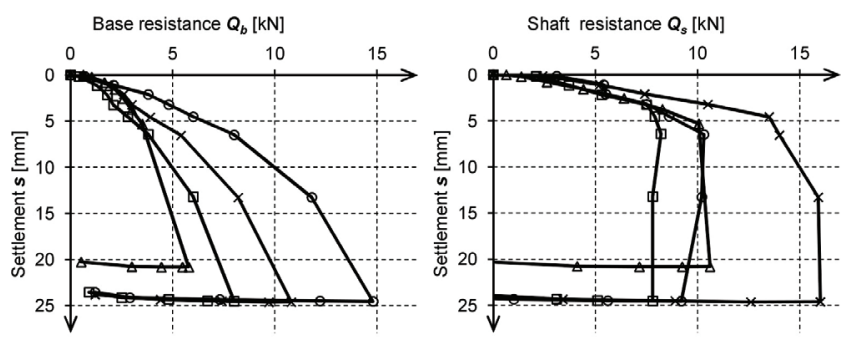

Fig. 8. Characteristics of shaft and base resistances of selected SDP piles from the group, compared with the same resistances of a single SDP pile

It can be seen that the base resistance of a single pile is smaller than the same resistances of any pile in the group. In the small range of settlement, the base resistance of the center pile is smaller than that of a single pile. In the case of shaft resistances we observe that single pile characteristic is close to that of the center pile, it is greater than the edge pile characteristic and smaller than corner pile characteristic.

In Figure 9, one can compare the global loadsettlement characteristic of SDP piles group with the summary characteristic of nine single SDP piles. As a representative characteristic of a single pile we have chosen the characteristic of pile PS2, for which the soil conditions were most similar to those in SDP group test.

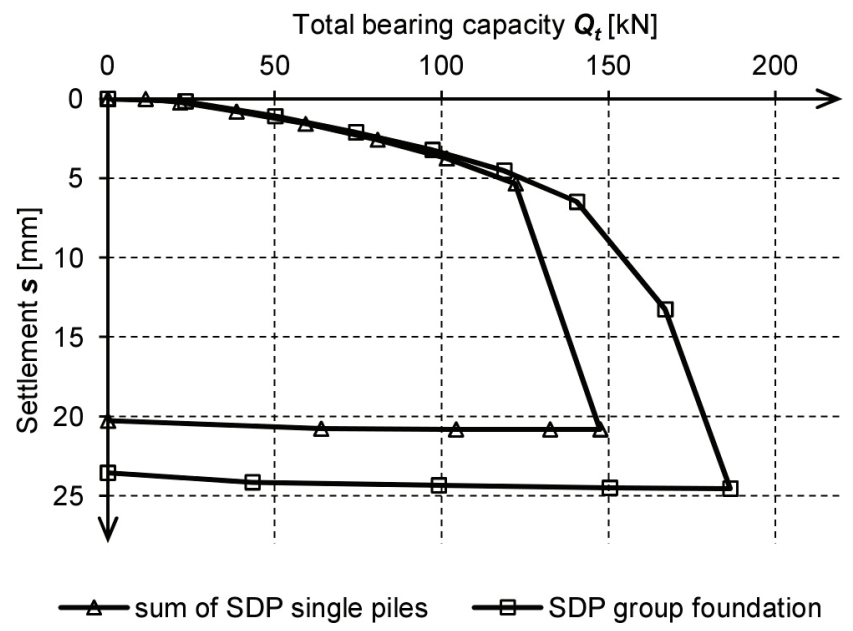

Fig. 9. Bearing capacity characteristics of SDP group foundation and sum of single SDP piles

It can be seen that the bearing capacity of SDP pile models working in group is higher than the summary bearing capacity of the same number of single piles. However, it should be noted that in the range of small settlements the load-settlement characteristics of piles in both cases are very similar.

\section{CONCLUSIONS}

In the paper, it has been demonstrated that the use of strain gauge measuring method can provide significant advantages in the study of pile model tests.

The knowledge of axial force distribution along the pile core and of the load distribution on piles in group foundation allowed us to formulate the following conclusions:

- the total bearing capacity of a group of SDP model piles is higher than the summed bearing capacity of the same number of single piles,

- the higher bearing capacity of pile group results from higher base resistances of piles working in a group compared to piles working separately; the shaft resistances of piles working in a group can be higher or smaller than the shaft resistance of piles working separately; it depends on the location of given pile in the group.

Future research work of the authors will focus on:

- the influence of the sequence of pile installation in a group on bearing capacity of separate piles,

- the influence of different soil conditions (sand density) on bearing capacity of a group of SDP piles,

- the phenomenon of SDP pile group interaction with non-cohesive soil.

\section{REFERENCES}

[1] Hofmann K., An Introduction to Stress Analysis and Transducer Design using Strain Gauge, HBM. Retrieved July 5, 2014, from HBM http://www.hbm.com/en/menu/tips-tricks/experimentalstress-analysis/reference-book/

[2] KRAsińsKi A., Model tests of screwed piles, Proceedings of the XIV Danube-European Conference on Geotechnical Engineering. From Research to Design in European Practice, 2-4 June 2010, Bratislava.

[3] KRASIŃSKI A., Screw displacement piles. Interaction with non-cohesive soil, Wydawnictwo Politechniki Gdańskiej, Gdańsk 2013, 60-75, (in Polish).

[4] KRAsiński A., Kusio T., Comparative model tests of SDP and CFA pile groups in non-cohesive soil, Proceedings of XVI French-Polish Colloquium of Soil and Rock Mechanics, Multiscale Modeling in Soil and Rock Mechanics, 7-10 July 2013 (CD), Montpellier. 